\title{
AVALIAÇÃO DA EFICIÊNCIA DE HERBICIDAS NO CONTROLE DE PLANTAS DANINHAS EM ALFAFA
}

\author{
Decreasing of weed plants using herbicides and herbicides mix in alfalfa crop \\ Wilson da Silva ${ }^{1}$, Duarte Vilela ${ }^{2}$, Tarcísio Cobucci ${ }^{3}$, Alexandre Bryan Heinemann ${ }^{2}$, \\ Fernando Alvarenga Reis ${ }^{4}$, Antônio Vander Pereira ${ }^{2}$, Reinaldo de Paula Ferreira ${ }^{2}$
}

\begin{abstract}
RESUMO
Objetivou-se neste trabalho avaliar a seletividade e a eficiência de herbicidas no controle de plantas daninhas na cultura da alfafa. Foram desenvolvidos dois experimentos em Anápolis, GO. No primeiro, avaliaram-se oito herbicidas (imazethapyr, MSMA, fomesafen, bentazon, chlorimuron-ethyl, imazamox) aplicados em pós-emergência da alfafa, e no segundo, seis misturas de herbicidas [(diuron + MSMA), (diuron + MSMA), (diuron + paraquat), (diuron + paraquat)] aplicados um dia após o corte da alfafa. Em ambos os experimentos, foram incluídas duas testemunhas (capinada e sem capina), sendo os tratamentos distribuídos em blocos ao acaso com quatro repetições. Os herbicidas como imazethapyr, MSMA, fomesafen, bentazon, chlorimuron-ethyl e imazamox foram seletivos à cultura da alfafa e eficientes no controle de plantas daninhas. As misturas dos herbicidas (diuron + MSMA) e (diuron + paraquat) aplicados logo após o corte da alfafa causaram danos às folhas e aos caules remanescentes. As brotações, todavia, surgiram isentas de toxicidade, apresentando crescimento e desenvolvimento normais. Essas misturas promoveram eficiente controle de plantas daninhas, e não afetaram o acúmulo de biomassa seca e altura de plantas em relação à testemunha capinada. O não-controle das plantas daninhas reduziu a produção de biomassa seca e a altura das plantas de alfafa em $74,5 \%$ e $42,8 \%$, respectivamente.
\end{abstract}

Termos para indexação: Medicago sativa, seletividade, mistura de herbicidas.

\begin{abstract}
The objectives of this study were to evaluate the efficiency and selectivity of herbicides on the weed plants control at the alfalfa crop. Two experiments were carried out at the Experimental Station of Agenciarural, located in Anápolis, GO. In the first experiment it was evaluated eight herbicides (imazethapyr, MSMA, fomesafen, bentazon, chlorimuron-ethyl and imazamox) post emergency and in the second experiment six different mixed of herbicides [(diuron + MSMA), (diuron + MSMA), (diuron + paraquat), (diuron + paraquat)] applied one day after the alfalfa harvesting date. For both experiments were included two checks (weedy check and no weedy check) and it was used a randomized block design, with four replications. The herbicides imazethapyr, MSMA, fomesafen, bentazon, chlorimuron-ethyl and imazamox were selective to the alfalfa crop and efficient for the weed plants control. The mixed of herbicides (diuron + MSMA) and (diuron + paraquat) applied after the harvesting date were responsible for damage on leaves and stem remaining. Although the new alfalfa budding did not show any signal of toxic and the development and growth was normal. These mix of herbicides showed an efficient weed plants control and did not affect the harvest dry matter and plant height comparing to the weedy check. The no weedy check reduced the plant dry matter and height in $74,5 \%$ and $42,8 \%$, respectively.
\end{abstract}

Index terms: Efficiency, Medicago sativa, selectivity.

(Recebido para publicação em 24 de abril de 2003 e aprovado em 19 de março de 2004)

\section{INTRODUÇÃO}

A cultura da alfafa apresenta crescimento e desenvolvimento inicial lento, necessitando de tratamentos especiais quanto ao controle de plantas daninhas em razão da alta sensibilidade desta cultura à sua interferência. Esta cultura é plantada geralmente em áreas que são rapidamente infestadas pelas invasoras, principalmente na fase de implantação. A composição específica da comunidade infestante é de fundamental importân-

\footnotetext{
1. Engenheiro Florestal, D.S. em Fitotecnia, Bolsista Desenvolvimento Científico Regional CNPq, Embrapa Gado de Leite - Embrapa Gado de Leite/NCO - Caixa Postal 179 - 75375-000 - Santo Antonio de Goiás, GO.

2. Engenheiros Agrônomos, Pesquisadores da Embrapa Gado de Leite, Dom Bosco - 36038-330 - Juiz de Fora, MG, vilela@cnpgl.embrapa.br, alexbh@cnpaf.embrapa.br.

3. Engenheiro Agrônomo, Pesquisador da Embrapa Arroz e Feijão, Caixa Postal 179 - 74001-970 - Goiânia, GO. cobucci@cnpaf.embrapa.br.

4. Zootecnista, Pesquisador da Agenciarural de Anápolis, upanaps@zaz.com.br.
} 
cia na determinação do grau de interferência, pois as espécies integrantes dessa comunidade variam bastante em relação aos seus hábitos de crescimento e exigência em recursos do meio.

A alfafa é vulnerável aos danos provocados pelas plantas invasoras, principalmente no estádio inicial de crescimento, impedindo o desenvolvimento adequado da cultura no campo (NUERNBERG et al., 1990) reduzindo a qualidade das sementes e da forrageira (PETERS e PETERS, 1992) e diminuindo na persistência do estande (SILVA et al., 2001). Dessa forma, o controle das plantas daninhas com herbicidas torna-se fundamental para garantir o sucesso do estabelecimento do alfafal. A demanda dessa forrageira requer alta qualidade e produtividade de biomassa durante o ano inteiro, a fim de atender às exigências dos animais de alta produção. Para isso, torna-se necessária a adequada correção dos fatores limitantes do crescimento e desenvolvimento da cultura, destacando-se aqueles relativos à fertilidade, disponibilidade de água do solo e controle de plantas daninhas.

$\mathrm{O}$ uso de herbicidas no manejo de plantas daninhas na cultura da alfafa constitui-se no método mais utilizado. Entretanto, faltam pesquisas quanto à tolerância da alfafa à seletividade dessa cultura aos novos herbicidas e/ou misturas de herbicidas, pois é comum no campo se observar baixa eficiência de controle de algumas espécies de plantas daninhas e alta toxicidade na cultura, principalmente quando essa está em início de desenvolvimento.

Para que um herbicida exerça a sua ação final, que é a morte da planta, basta que uma pequena porcentagem seja absorvida e translocada até atingir o local de ação (MORELAND, 1980). A seletividade dos herbicidas aplicados em pós-emergência é função da quantidade interceptada e retida pela parte aérea da planta e da quantidade absorvida e translocada para o sítio de ação do herbicida (ASHTON e CRAFTS, 1973). Com relação aos produtos aplicados ao solo, como os de ação residual, a tolerância da planta ao herbicida é influenciada pelo seu posicionamento e bioatividade no perfil do solo. A capacidade da planta em degradar a molécula do produto exerce também influência na sua tolerância aos herbicidas. A eficiência dos herbicidas depende das características físico-químicas dos solos e dos tipos de herbicidas, das condições climáticas, das características morfofisiológicas das culturas e das plantas daninhas (SILVA, 2000).

Diante do exposto, com este trabalho objetivouse avaliar a seletividade e a eficiência de alguns herbicidas latifolicidas sobre o controle de plantas daninhas na implantação da cultura da alfafa e a eficiência das misturas de herbicidas no controle de plantas daninhas após o corte da alfafa.

\section{MATERIAL E MÉTODOS}

O experimento foi conduzido, em condições de campo, na Estação Experimental da Agenciarural de Anápolis, GO. As análises do material de solo (camada de 0 a $20 \mathrm{~cm}$ ) foram realizadas de acordo com métodos apresentados pela Embrapa (1997). Os valores foram: 45,6\% de areia, $16,7 \%$ de silte, $37,7 \%$ de argila, teor de matéria orgânica de 2,2\% e o pH 5,7. O solo da área experimental é classificado como Latossolo Vermelho distrófico, de textura argilosa. No preparo do solo, realizado 90 dias antes do plantio da alfafa, aplicaram-se 2 t/ha de calcário dolomítico e $300 \mathrm{~kg} / \mathrm{ha}$ da formulação NPK 4-14-8. Por ocasião da semeadura da alfafa, aplicaram-se ainda no sulco de plantio $800 \mathrm{~kg} / \mathrm{ha}$ da formulação NPK 4-14-8, $120 \mathrm{~kg} / \mathrm{ha}$ de $\mathrm{KCl}$ e $50 \mathrm{~kg} / \mathrm{ha}$ de FTE - 12. A semeadura foi realizada na profundidade de $2 \mathrm{~cm}$, distribuindo-se o equivalente a 20 $\mathrm{kg} \mathrm{ha}^{-1}$ de sementes da cultivar Crioula, previamente inoculadas com Rhizobium meliloti.

As parcelas experimentais foram constituídas de dez linhas de 5,0 $\mathrm{m}$ de comprimento, espaçadas entre si de $0,20 \mathrm{~m}$, sendo somente as seis fileiras centrais, menos de 0,50 m de cada extremidade, consideradas a área útil. As parcelas foram irrigadas de acordo com a necessidade da cultura.

A aplicação dos herbicidas para controle das plantas daninhas dicotiledôneas foi realizada aos 25 dias após a emergência (DAE), que ocorreu 5 dias após o plantio. Para evitar interferência das gramíneas, toda a área experimental, exceto a testemunha capinada, foi pulverizada com $48 \mathrm{~g} /$ ha de haloxyfop-methyl, três dias após a aplicação dos herbicidas latifolicidas. Usou-se pulverizador costal, pressurizado a $\mathrm{CO}_{2}$, com pressão de $30 \mathrm{lb} / \mathrm{pol}^{2}$, equipado com barra com quatro bicos do tipo leque, 110.03 , espaçados entre si de $0,50 \mathrm{~m}$, com consumo de 200 L/ha de calda. Por ocasião da aplicação, o solo estava úmido, o céu claro, e a velocidade do vento era de $1,5 \mathrm{~km} / \mathrm{h}$, às $8 \mathrm{~h}$. A temperatura do ar era de $23^{\circ} \mathrm{C}$ e a umidade relativa do ar, $79 \%$.

Os efeitos dos herbicidas sobre a cultura da alfafa foram avaliados aos 7, 14, 21 e 28 dias após a aplicação (DAA), de acordo com os sintomas visuais de fitotoxicidade, numa escala de 0 (zero) a $100 \%$, em que 0 (zero) equivale a nenhum dano visível na planta e 100, à morte da planta (FRANS, 1972).

A avaliação de controle das espécies invasoras foi feita nas parcelas de $10 \mathrm{~m}^{2}$ aos 30,60 e 90 DAA, 
adotando-se a escala visual de $0,0 \%$ (ausência de controle) a $100 \%$ (controle total). No tratamento adicional (parcela capinada), as plantas daninhas foram controladas, mensalmente, com enxada, até os 90 DAA.

Os herbicidas avaliados, em g/ha, foram: imazethapyr (100), MSMA (4320), fomesafen (200), bentazon (720), chlorimuron-ethyl $(15,0)$ e imazamox (28). Os oito tratamentos avaliados (seis herbicidas + duas testemunhas - capinada e sem capina) foram distribuídos em blocos ao acaso, com quatro repetições. A biomassa seca e a altura de plantas foram comparadas pelo teste $\mathrm{F}(\mathrm{P}<0,05)$. $\mathrm{O}$ efeito de herbicida foi comparado com a testemunha capinada pelo teste de Dunnett, a 5\% de probabilidade. Para as outras características avaliadas, como porcentagem de controle de plantas daninhas e sintomas de toxicidade à cultura, foram feitas análises descritivas dos dados.

Para avaliar os efeitos dos tratamentos após o corte da alfafa, as misturas dos herbicidas latifolicidas [diuron (1500) + MSMA (2880), diuron (2000) + MSMA (3600), diuron (1500) + paraquat (400) e diuron $(1500)+$ paraquat $(500)]$ foram aplicadas sobre a parte remanescente da cultura, um dia após seu corte. Os seis tratamentos avaliados (quatro misturas de herbicidas + duas testemunhas - capinada e sem capina) foram distribuídos em blocos ao acaso, com quatro repetições. Por ocasião dessa, o solo estava úmido, o céu claro, e a velocidade do vento era de $2,5 \mathrm{~km} / \mathrm{h}$, às $8 \mathrm{~h} 30$. A temperatura era de $24^{\circ} \mathrm{C}$ e a umidade relativa, $73 \%$.

A avaliação de controle das espécies invasoras foi realizada na parcela de $10 \mathrm{~m}^{2}$, aos 15 e $30 \mathrm{DAA}$, adotando-se a escala visual de 0,0 (ausência de controle) e 100 (controle total). No tratamento adicional, as plantas daninhas foram controladas quinzenalmente com enxada, até aos 35 DAA.

A altura $(\mathrm{cm})$ da alfafa foi determinada medindo-se da região do nível do solo ao ápice da planta aos 35 DAA, na área útil da parcela. Ainda nessa época, avaliou-se a biomassa seca da parte aérea (g) das plantas, que foram cortadas rente ao solo e secas em estufa com circulação forçada de ar, à temperatura de $70^{\circ} \mathrm{C}$, até atingirem biomassa constante. A biomassa seca e altura de plantas foram comparadas pelo teste $\mathrm{F}(\mathrm{P}<0,05)$. O efeito dos herbicidas e das misturas de herbicida foi comparado com a testemunha capinada pelo teste de Dunnett, a $5 \%$ de probabilidade.

\section{RESULTADOS E DISCUSSÃO}

O imazethapyr e o imazamox não afetaram as plantas de alfafa (Tabela 1). Essas, quando tratadas com MSMA, chlorimuron-ethyl, fomesafen e bentazon, apresentaram sintomas iniciais de toxicidade com recuperação total, após aos 14 DAA, à exceção das plantas tratadas com o fomesafen que, aos 21 DAA, ainda apresentavam sintomas $5,5 \%$ de toxidez, na escala de 0 a $100 \%$. Todavia, estes danos estavam restritos apenas às folhas mais novas, e não no meristema apical. Resultados semelhantes foram observados por (SILVA et al., 2001). Um dos problemas para o estabelecimento da cultura da alfafa no campo tem sido a fitotoxicidade dos herbicidas latifolicidas aplicados em pós-emergência (KUST, 1969).

$\mathrm{Na}$ avaliação de controle de plantas daninhas realizadas, aos 30 DAA dos herbicidas de pósemergência, todos os produtos promoveram controle de bom (> 70\%) a ótimo (> 90\%) das espécies daninhas presentes na área experimental (Tabela 2). A espécie dominante foi eficientemente controlada (> 85\%) por todos os herbicidas.

$\mathrm{Na}$ avaliação aos 60 DAA, verificou-se pequena reinfestação da área devida à recuperação de algumas plantas de $P$. oleracea e $C$. benghalensis (Tabela 3). Por ocasião da colheita da alfafa aos 90 DAA, observou-se pouca incidência das invasoras, semelhante à época de avaliação aos 60 DAA. Isso ocorreu devido à forte competição exercida pela alfafa, que se apresentava com elevado estande. Com isso, a cultura proporcionou sombreamento, dificultando novas reinfestações.

Aos 90 dias da aplicação dos herbicidas (Tabela 4), não foram constatadas diferenças no acúmulo de biomassa seca da parte aérea entre as plantas daninhas tratadas com imazethapyr, MSMA, fomesafen, chlorimuron-ethyl, bentazon e imazamox e a testemunha capinada. A menor biomassa seca produzida pelas plantas da testemunha sem capina foi em virtude da interferência das plantas daninhas com a cultura, a qual causou redução de $74,5 \%$ no acúmulo de biomassa seca. Resultados semelhantes foram observados por (SILVA et al., 2001).

Também a altura de plantas foi reduzida $(42,8 \%)$ pela interferência das plantas daninhas (Tabela). Não foi observada diferença entre a altura da testemunha capinada com os tratamentos - imazethapyr, MSMA, fomesafen, bentazon, chlorimuron-ethyl e imazamox, aos 90 DAA, indicando boa seletividade dos tratamentos. 
TABELA 1 - Grau médio de toxicidade (\%), com o respectivo desvio-padrão das plantas de alfafa, avaliadas aos 7 , 14, 21 e 28 DAA, em resposta aos herbicidas aplicados em pós-emergência. Anápolis, GO, 2002.

\begin{tabular}{lccccc}
\hline \multicolumn{6}{c}{ Dias após a aplicação (DAA) } \\
\hline \multicolumn{1}{c}{ Herbicidas } & Doses (g/ha) & $\mathbf{7}$ & $\mathbf{1 4}$ & $\mathbf{2 1}$ & $\mathbf{2 8}$ \\
\hline imazethapyr & \multicolumn{7}{c}{ Grau médio de toxicidade (\%) } \\
MSMA & 100 & 0,0 & 0,0 & 0,0 & 0,0 \\
fomesafen & 4320 & $6,2 \pm 1,1$ & $2,5 \pm 1,0$ & 0,0 & 0,0 \\
bentazon & 200 & $23,1 \pm 8,2$ & $8,8 \pm 3,7$ & $5,5 \pm 2,1$ & 0,0 \\
chlorimuron-ethyl & 720 & $11,2 \pm 2,4$ & $4,7 \pm 1,3$ & 0,0 & 0,0 \\
imazamox & 15 & $4,3 \pm 1,3$ & 0,0 & 0,0 & 0,0 \\
testemunha sem capina & 28 & 0,0 & 0,0 & 0,0 & 0,0 \\
\hline
\end{tabular}

O graminicida haloxyfop-methyl foi aplicado na dose única de $48 \mathrm{~g} \mathrm{ha}^{-1}$, três dias após à aplicação dos latifolicidas.

TABELA 2 - Porcentagem de controle das plantas daninhas, em $10 \mathrm{~m}^{2}$, avaliadas aos 30 DAA em resposta à dose de herbicidas aplicados em pós-emergência da alfafa. Anápolis, GO, 2002.

\begin{tabular}{lccccccc}
\hline \multicolumn{1}{c}{ Herbicidas } & $\begin{array}{c}\text { Doses } \\
\text { g/ha }\end{array}$ & $\begin{array}{c}\text { Ageratum } \\
\text { conyzoides }\end{array}$ & $\begin{array}{c}\text { Amaranthus } \\
\text { deflexus }\end{array}$ & $\begin{array}{c}\text { Portulaca } \\
\text { oleracea }\end{array}$ & $\begin{array}{c}\text { Sonchus } \\
\text { oleraceus }\end{array}$ & $\begin{array}{c}\text { Commelina } \\
\text { benghalensis }\end{array}$ & Outras** \\
\hline & \multicolumn{2}{c}{ Controle de plantas daninhas (\%) por espécies* } \\
\hline imazethapyr & 100 & 86,9 & 96,1 & 88,2 & 71,2 & 84,1 & 93,5 \\
MSMA & 4320 & 97,0 & 97,5 & 96,5 & 75,0 & 82,5 & 92,8 \\
fomesafen & 200 & 96,8 & 97,6 & 89,5 & 73,4 & 81,6 & 93,4 \\
bentazon & 720 & 97,9 & 82,3 & 88,7 & 79,6 & 82,8 & 88,1 \\
Chlorimuron-ethyl & 15 & 87,8 & 81,4 & 85,6 & 76,2 & 84,3 & 92,7 \\
imazamox & 28 & 95,8 & 86,6 & 77,3 & 78,1 & 84,4 & 88,7 \\
$\begin{array}{l}\text { testemunha* sem } \\
\text { capina }\end{array}$ & - & 0,0 & 0,0 & 0,0 & 0,0 & 0,0 & 0,0 \\
\hline
\end{tabular}

*Número de plantas daninhas com respectivo desvio-padrão, A. conyzoides $318 \pm(32,5)$, A. deflexus de $14 \pm(3,5)$, P. oleracea 36 $\pm(9,9)$, S. oleraceus $12 \pm(2,2)$, C. benghalensis $46 \pm(9,7)$,

**Ipomoea grandifolia $6 \pm(2,7)$, Galinsoga parviflora $17 \pm(6,6)$ e Bidens pilosa $7 \pm(2,8)$. 
Quanto à tolerância e eficácia das mistura de herbicidas aplicados após o corte da alfafa, observou-se que a aplicação da mistura (diuron + paraquat), logo após o corte da cultura, provocou danos nas folhas e caules remanescentes após o corte, com clorose, seguida de necrose. Todavia, as brotações que surgiram após a aplicações dessa mistura apresentaram folhas novas, sem nenhum dano, com crescimento e desenvolvimento normais em sua parte aérea, dentro de seis dias. No entanto, para a mistura (diuron + MSMA), independente da dose, provocou injúria menor e também com rápida recuperação da cultura. Essas misturas acima citadas proporcionaram controle acima de $91,3 \%$ de todas espécies de invasoras presentes na área, na avaliação realizada aos 15 DAA (Tabela 5). Aos 30 DAA da condução do experimento, não houve incidência de novas plantas daninhas. As misturas "diuron + MSMA" e "diuron + paraquat" foram aplicadas quando Braquiaria brizantha e Digitaria horizontalis encontravam-se no estádio de desenvolvimento "póstardia". Dessa forma, propiciaram controle acima de 90,1\% dessas duas espécies.

TABELA 3 - Porcentagem de controle das plantas daninhas, em $10 \mathrm{~m}^{2}$, avaliadas aos 60 DAA em resposta à dose de herbicidas aplicados em pós-emergência da alfafa. Anápolis, GO, 2002.

\begin{tabular}{|c|c|c|c|c|c|c|c|}
\hline Herbicidas & $\begin{array}{c}\text { Doses } \\
\text { g/ha }\end{array}$ & $\begin{array}{l}\text { Ageratum } \\
\text { conyzoides }\end{array}$ & $\begin{array}{c}\text { Amaranthus } \\
\text { deflexus }\end{array}$ & $\begin{array}{c}\text { Portulaca } \\
\text { oleracea }\end{array}$ & $\begin{array}{c}\text { Sonchus } \\
\text { oleraceus }\end{array}$ & $\begin{array}{c}\text { Commelina } \\
\text { benghalensis }\end{array}$ & Outras** \\
\hline & \multicolumn{7}{|c|}{ Controle de plantas daninhas $(\%)$ por espécies* } \\
\hline imazethapyr & 100 & 84,2 & 93,1 & 84,2 & 70,0 & 83,0 & 91,5 \\
\hline MSMA & 4320 & 95,1 & 94,2 & 93,4 & 72,0 & 80,2 & 91,1 \\
\hline fomesafen & 200 & 94,5 & 95,2 & 86,2 & 70,9 & 78,1 & 90,6 \\
\hline bentazon & 720 & 94,8 & 80,1 & 85,6 & 77,7 & 79,8 & 84,9 \\
\hline Chlorimuron-ethyl & 15 & 84,2 & 80,8 & 82,3 & 74,4 & 82,2 & 90,2 \\
\hline imazamox & 28 & 93,7 & 83,7 & 73,3 & 76,4 & 80,1 & 86,7 \\
\hline $\begin{array}{l}\text { testemunha* sem ca- } \\
\text { pina }\end{array}$ & - & 0,0 & 0,0 & 0,0 & 0,0 & 0,0 & 0,0 \\
\hline
\end{tabular}

*Número de plantas daninhas com respectivo desvio-padrão, A. conyzoides $318 \pm(32,5)$, A. deflexus de $14 \pm(3,5)$, P. oleracea 36 $\pm(9,9)$, S. oleraceus $12 \pm(2,2)$, C. benghalensis $46 \pm(9,7)$,

**Ipomoea grandifolia $6 \pm(2,7)$, Galinsoga parviflora $17 \pm(6,6)$ e Bidens pilosa $7 \pm(2,8)$.

TABELA 4 - Biomassa seca da parte aérea e altura de plantas da cultivar Crioula, avaliadas aos 90 DAA, em resposta às misturas de herbicidas aplicadas em pós-emergência da alfafa. Anápolis, GO, 2002.

\begin{tabular}{lcc}
\hline \multicolumn{1}{c}{$\begin{array}{c}\text { Mistura de herbicida } \\
\text { (g/ha) }\end{array}$} & \multicolumn{2}{c}{ Características avaliadas em 1,0 $\mathbf{~ m}^{\mathbf{2}}$} \\
\cline { 2 - 3 } & Biomassa seca $(\mathbf{g})$ & Altura $(\mathbf{c m})$ \\
\hline imazethapyr & 132,5 & 49,5 \\
MSMA & 131,7 & 48,0 \\
fomesafen & 129,4 & 47,0 \\
bentazon & 128,3 & 47,5 \\
chlorimuron-ethyl & 128,9 & 47,5 \\
imazamox & 128,5 & 46,5 \\
testemunha capinada & 132,5 & 49,8 \\
testemunha sem capina & $33,7 *$ & $28,5 *$ \\
\hline
\end{tabular}

* Estatisticamente diferente da testemunha capinada pelo testes Dunnett $(\mathbf{P}<0,05)$. 
TABELA 5 - Porcentagem de controle de plantas daninhas, em $10 \mathrm{~m}^{2}$, avaliadas aos 15 DAA, em resposta às doses dos herbicidas aplicadas após o corte da alfafa. Anápolis, GO, 2002.

\begin{tabular}{lcccccc}
\hline \multicolumn{1}{c}{ Herbicidas (g/ha) } & $\begin{array}{c}\text { Bidens } \\
\text { pilosa }\end{array}$ & $\begin{array}{c}\text { Commelina } \\
\text { benghalensis }\end{array}$ & $\begin{array}{c}\text { Amaranthus } \\
\text { deflexus }\end{array}$ & $\begin{array}{c}\text { Ageratum } \\
\text { conyzoides }\end{array}$ & $\begin{array}{c}\text { Portulaca } \\
\text { oleracea }\end{array}$ & Gramíneas* \\
\hline & \multicolumn{6}{c}{ Controle de plantas daninhas (\%) por espécies } \\
\hline diuron (1500) + MSMA (2880) & 95,9 & 91,3 & 97,1 & 97,1 & 95,2 & 90,2 \\
& & & & & & \\
diuron (2000) + MSMA (3600) & 97,2 & 93,2 & 98,3 & 97,1 & 97,3 & 93,4 \\
diuron (1500) + paraquat (400) & 95,5 & 97,9 & 95,0 & 94,0 & 95,7 & 90,1 \\
diuron (1500) + paraquat (500) & 96,2 & 98,5 & 97,5 & 97,0 & 96,9 & 92,2 \\
testemunha sem capina & 0,0 & 0,0 & 0,0 & 0,0 & 0,0 & 0,0 \\
\hline
\end{tabular}

*Brachiaria brizantha e Digitaria horizontalis

TABELA 6 - Biomassa seca da parte aérea e altura de plantas da cultivar Crioula, avaliadas aos 35 DAA, em resposta às misturas de herbicidas aplicadas após o corte da alfafa. Anápolis, GO, 2002.

\begin{tabular}{|c|c|c|c|}
\hline \multirow[b]{2}{*}{ Mistura de herbicida } & \multirow[b]{2}{*}{ (g/ha) } & \multicolumn{2}{|c|}{ Características avaliadas em $1,0 \mathrm{~m}^{2}$} \\
\hline & & Biomassa seca (g) & Altura (cm) \\
\hline Diuron (1.500) + MSMA (2.880) & & 237,2 & 49,8 \\
\hline Diuron (2.000) + MSMA (3.600) & & 241,0 & 48,0 \\
\hline Diuron $(1.500)+$ paraquat (400) & & 239,2 & 47,0 \\
\hline Diuron $(1.500)+$ paraquat (500) & & 243,4 & 47,5 \\
\hline testemunha capinada & & 242,0 & 47,5 \\
\hline testemunha sem capina & & $144,2 *$ & $24,5 *$ \\
\hline
\end{tabular}

*Estatisticamente diferente da testemunha capinada pelo testes Dunnett $(\mathbf{P}<0,05)$.

Aos 35 dias da aplicação dos herbicidas, não foram constatadas diferenças na biomassa seca da parte aérea e altura de plantas entre as misturas e a testemunha capinada (Tabela 6). Na testemunha sem capina, a redução da biomassa foi de $40,41 \%$ e da altura de $48,42 \%$, respectivamente, quando comparada com a testemunha capinada.

\section{CONCLUSÕES}

Os herbicidas imazethapyr, MSMA, fomesafen, bentazon, chlorimuron-ethyl e imazamox foram seletivos para a cultura da alfafa, e proporcionaram eficientes controles das plantas daninhas presentes na área.

As misturas (diuron + MSMA) e (diuron + paraquat) aplicadas logo após o corte da alfafa proporcionaram danos nas folhas e caules remanescentes. Todavia, as brotações novas ficaram isentas de fitotoxicidade, com crescimento e desenvolvimento normais em sua parte aérea, além disso, promovera eficiente controle de plantas daninhas.

A interferência das plantas daninhas na cultura da alfafa reduziu a produção de biomassa seca em $74,5 \%$ e a altura em $42,8 \%$.

\section{REFERÊNCIAS BIBLIOGRÁFICAS}

ASHTON, F. M.; CRAFTS, A. S. Mode of action of herbicides. New York: John Wiley \& Sons, 1973. $504 \mathrm{p}$.

EMPRESA BRASILEIRA DE PESQUISA AGROPECUÁRIA. Serviço Nacional de Levantamento e Conservação de Solos. Manual e métodos de análise de solo. Rio de Janeiro, 1997. 212 p. 
FRANS, R. W. Measuring plant response. In: WILKINSON, R. E. (Ed.). Research methods in weed science. Puerto Rico: Weed Science Society, 1972. p. 28-41.

KUST, C. A. Selective control of hoary alyssum in alfalfa. Weed Science, Champaign, v. 17, p. 99-101, 1969.

MORELAND, D. E. Mechanisms of action of herbicides. Annual Plant Physiology, Chicago, v. 31, p. 597-638, 1980.

NUERNBERG, N. J.; MILAN, P. A.; SILVEIRA, C. A. M. Manual de produção da alfafa. Florianópolis: EMPASC, 1990. 102 p.
PETERS, E. J.; PETERS, R. A. Weeds and control. In: Alfalfa science and technology. Madison: Wisconsin, 1992. $812 \mathrm{p}$.

SILVA, A. A. Controle de plantas daninhas. In: ASSOCIAÇÃO BRASILEIRA DE EDUCAÇÃO AGRÍCOLA SUPERIOR. Curso de proteção de plantas. Brasília, DF, 2000. p. 133-172.

SILVA, W.; DUARTE, V.; FERREIRA, L. R.; FERREIRA, R. P.; FERREIRA, F. A. Tolerância da alfafa (Medicago sativa L) a diferentes herbicidas aplicados em pré-emergência e pós-emergência. Revista Ceres, Viçosa, v. 48, n. 278, p. 415-425, 2001. 